\title{
Challenges of the two-year manuscript: Engaging in reflective practice with a manuscript about reflective practice
}

Jolene M Miller, MLS, AHIP

Director, Assistant Professor

Mulford Health Science Library

The University of Toledo

Toledo, $\mathrm{OH}$

In January, one of my manuscripts was published in the Journal of the Medical Library Association [1]. I was thrilled that the manuscript was published by my firstchoice journal; I was not thrilled that it took me over two years to write and submit it. After reflecting on my process, I realized that if there is a concept of writing management (similar to time management), I was sorely lacking those skills. Given that my research focused on reflective practice, sharing my reflective process to better understand my challenges with the two-year manuscript with the readers of Hypothesis is a natural next step.

Natural next steps are not necessarily easy ones. "Why would I want to tell anyone that I failed, let alone publish it in a journal with substantial readership? I don't want my colleagues, and especially not my boss, to know that my project didn't work, so no way would I want to tell the world" [2]. Indeed, why would anyone do such a thing? I cannot deny that I am more than a little uncomfortable sharing the results of my reflection - after all, I want you to think that I am competent and have it together all the time. That said, I hope that this column will help other librarians who encounter similar writing management problems, allowing them to intervene sooner rather than later.

Since I used reflective practice to review my writing process and will be talking about the process in this column, l'd like to share a bit about reflective practice before delving into my writing woes. Reflective practice is intentionally doing what we all do naturally: thinking about situations (often those with surprising or disappointing outcomes) to figure out what happened. It is different from ruminating, when someone replays a negative situation in their head repeatedly but never reaches the point of figuring out what went wrong and how to make improvements. The goal of reflective practice is to identify and make changes that can improve future performance including doing something differently, thinking about something or someone differently, or updating understanding of one's role and/or identity.

Reflective practice has three basic steps [3-5] though many models of reflective practice add additional steps, questions, and alternative perspectives: (1) describe the event (What happened? What did I do? What did others do? How was I feeling? What was I thinking?); (2) reflect on the event (What really happened? How might others have perceived it? What if I had done $Y$ instead of $X$ ?); and (3) identify potential changes for future situations (Do I need to change a process? Do I need to change how I approach 
a situation? Do I need to change how I think about a person, a situation, or my role as a librarian?). I do not always use a model for reflection, but when I do, it is Graham Gibbs' model. This model was developed as a "full structured debriefing to the stages of the experiential learning cycle" that teachers can use with their learners [6]. It works for reflective practice because reflection helps us learn from our experiences. The Gibbs model expands the basic three steps described above to six steps: Description, Feelings, Evaluation, Analysis, Conclusion, and Action Plan. This model underpins the analysis of my writing challenges. It is my hope that not only will readers learn how to be more expedient when preparing manuscripts, but that they will also see how a model of reflective practice can be applied to library work.

Using intentional reflection to improve professional practice can be an individual pursuit through pondering and/or writing alone or it can be communal by having conversations with a peer, coach, mentor, or a small group. I started individual reflective work about eighteen months into the research project, when it felt like I would literally never finish the manuscript. At about the same time, I began talking with trusted others: a colleague, my therapist, and my spiritual director. Each had a different perspective, which led to different observations and suggestions. My colleague approached my situation from perspective of a tenured librarian who has experienced this themselves. They were able to share what worked for them. My therapist approached it from a timeand stress-management perspective, with the stress management skills being more helpful than I expected. My spiritual director approached it from a values-based view, inviting me to consider why I was doing research and writing for publication in the first place in order to clarify my motivation. This column moves my reflection to a broader community. I am sharing the experience with you in hopes that it will help you. I am also hoping that you might share your observations with me in return.

\section{THE GIBBS REFLECTION MODEL IN ACTION}

\section{Description}

The first step in the Gibbs model is a non-judgmental description of the situation. It always includes one's own perceptions and understandings, but it can also include others' feedback and external documentation such as evaluation forms.

In spring of 2017 , I surveyed health science librarians using an online questionnaire about their engagement in reflective practice and what they identified as the benefits of and barriers to engaging in reflective practice. It took two years to write up the results and submit the manuscript for publication. I would work regularly on it for a time, then I would set it aside for weeks or months as urgent library projects took priority. When I returned to the manuscript, it took time to remember where I was in the project and where I was headed. My reflective conversations provided additional information to consider, such as the 
role that stress played in the situation and how I had been treating the manuscript as one more hoop for the tenure process, rather than as an opportunity to better understand our profession.

\section{Feelings}

One of the benefits of the Gibbs model is that it explicitly asks about emotions to provide insight into a situation. Remembering the feelings experienced during a situation and paying attention to those feelings while reflecting invariably enriches my results while ignoring the emotions experienced in a situation leads to missed cues that could have helped me understand what happened. On the other hand, if a situation was highly emotional, I might need to give myself some space before reflecting, so emotions do not derail the reflection.

While working on the two-year manuscript, my feelings varied. There were times early on when I felt great. In hindsight, I was feeling great because I was regularly spending time in a local coffee shop working on the manuscript (very cool and academic). During that time, however, I had no clue how little progress I had to show for my time. When I finally compared my progress to the amount of time that had passed, I felt frustrated with the project and angry with myself. In this situation, feelings helped me identify the aspect of the process that needed my attention. My therapist was particularly helpful at the frustration and anger part of my reflection. With careful application of self-compassion, I was able to see beyond where I was to where I wanted to be - a submitted manuscript.

\section{Evaluation}

The first two stages of the Gibbs model are purely descriptive. At the evaluation stage, judgment finally plays a role: What was good or bad about the experience, in terms of the overall experience and in terms of specific parts of the experience?

In my case, while I was pleased by the positive outcome of a published manuscript, I was not happy with my performance, specifically that it took so long to prepare the manuscript. For this column, I am reflecting on what I perceived to be a negative aspect of the situation: I didn't manage my writing well. Reflective practice can also center on positive aspects and situations.

\section{Analysis}

The analysis step of this model is where deeper exploration of the situation takes place. In previous steps, information was gathered and judgements made. This step looks at the information to determine why some things went well and why other things didn't go so well. To quote Gibbs, "What was really going on?" [6]. 
As I looked back over my writing process, both while I was working on the manuscript and when it was completed, I identified one primary factor contributing to the slow speed of my process: writing management. Specifically, I had difficulty staying focused on and engaged with my writing in the midst of competing work and home demands. My professional situation is not unique; we all have more projects than we can reasonably fit into the workweek. I have responsibilities in a variety of areas: providing information and research support to my liaison areas; coordinating information and access services at my library; dealing with administrative issues, including shepherding the library renovations that took place while I was writing; representing my library in University Libraries meetings; assisting with program accreditation; committee service; etc. On top of work demands, I had purchased a new home that required minor renovations and, at the same time, I had an old home that needed work to be ready for market. More often than I anticipated, these work and personal responsibilities led me to put my writing aside, sometimes for months at a time. This obviously delayed the completion of the manuscript, but the delay was compounded by the fact that for every break, I had to take extra time to review my work and remember where I was in the project.

\section{Conclusions}

In this step, the Gibbs model invites conclusions as a result of the previous steps. The model calls for both general conclusions (such as the challenges librarians face in terms of managing their writing) as well as those that are more personal (the challenges I personally face and how I think and work).

While it is difficult to make general conclusions in this situation, I can tentatively say that given the natures of librarianship and of scholarly writing, completing manuscripts can be challenging for librarians. Personally, my reflection made it obvious to me that relying solely upon internal resources, such as finding time for writing and relying upon my memory to help me pick up where I left off, was not enough to help me manage my writing in an effective way. I needed to identify one or more external tools to support my writing. In other areas of my work life, I use external tool such as a calendar for my schedule and my Bullet Journal [7] to keep on top of tasks and projects. Perhaps something similar would help with writing management.

\section{Action plan}

In the action plan step, Gibbs invites us to identify what needs to change (if anything) based on the results of analysis and conclusions. At this point, it is important 
that the action plan reflects the conclusions so that selected strategies will target the actual issues and not assumed ones.

What I learned through this reflection is that I cannot rely solely on what I had been doing: writing when I had time and assuming that I would remember my thought process when I paused my project. As noted in the conclusion section, I needed one or more external tools to keep me on track. I implemented two actions. First, I started a weekly "Write on Site" session at my library to help support student and faculty writing including my own. For an hour each week, the library offers a drop-in session for students and faculty. Following the Pomodoro Technique ${ }^{8}$ [8], we have two 25-minute work sprints, with a 5-minute break between. "Write on Site" provides informal accountability. Participants do not report on progress toward writing goals as would happen in writing groups, but each week, we show up and write. When I show up and write, sometimes I end up with a "shitty first draft" [9] of a section, and other times, I end up with a solid piece of writing. For me, the most important benefit of this program is staying engaged with my writing. I never go more than a week without working on it (unless there is a global pandemic; in 2020, I am cutting myself some slack, and you should cut yourself some too). This regular engagement reduces wasted time reviewing the project to remember where I was and what I was thinking.

Another tool that I adopted near the end of the project was a research log. Research logs (or diaries) have long been used in qualitative research as a way to help researchers clarify assumptions and biases that may have an impact on the research, improving transparency [10]. The goal for my research log was to capture where I was in my writing process, including what I expected my next actions to be. Initially, my use of the log was haphazard, with scattered brief notes to myself about the project or ideas for future projects, with little or no follow-up. I am now using it in an intentional way to better capture my process with narrative descriptions of research ideas, summarizing the direction of the project to make it easier when I return to it, and reflecting on my research and writing process using guiding questions (Table 1). As you can see from the questions, I've incorporated some Gibbs-inspired questions in order to identify issues before they cause larger problems. I write my research log longhand because it physically slows me down, which leads to a mental slowing down. The mental slow-down allows me to think more deeply about my project.

Why did I decide on these two interventions? I selected "Write on Site" because I had been searching the web for something to help me stay focused on writing. When I found the "Shut Up and Write!" post on the blog The Thesis Whisperer [11], I was intrigued by the idea of getting together to write every week. We scheduled a time and advertised it to campus. Usually there were a 
couple of us, but before the library closed due to the pandemic in March 2020, there were three of us getting together regularly. In terms of the research log, this was something I adapted from a technique that I promote to my physician assistant students when they begin their scholarly projects. While I retained part of what I recommend for the students (jotting down thoughts and ideas during the research process), I generated the questions shown in Table 1 to help me focus on the information that I felt would help my writing the most.

- What did I accomplish during this work period?

- Where am I headed with this project?

- What is my next action?

- What challenges am I encountering?

- What might be the reason for these challenges?

- How can I overcome these challenges?

- How could I prevent them in the future?

Table 1. Guiding questions for my research log

\section{FUTURE PLANS}

While "Write on Site" and the research log have been helpful, there are additional tools I would like to explore. One is a mental shift - I need to treat writing projects like any other project. I mentioned above about how I use my Bullet Journal to manage projects, but I have yet to apply the tool to writing in a meaningful way. Also, I would like to increase my accountability to others beyond the informal accountability of "Write on Site". A colleague and I tried email accountability for a couple of months, but our technique (sending each other emails once a week with a report on what we did and what our goals were for the upcoming week) was not particularly helpful for either of us. Participating in a writing accountability group that met regularly might be helpful, not only report on progress on writing projects but also to discuss writing challenges and solutions and to celebrate achievements [12-14]. Given that so many of us are now familiar with an assortment of videoconferencing software, the time might be right to explore an online medical/health science librarian writing accountability group using one of these platforms.

\section{META-REFLECTION}

One thing that I value about reflective practice is its iterative nature. As I write this column, and again as I make revisions, I am engaging in meta-reflection - reflecting on my reflection - and understanding more about the situation. As I reread what I wrote in the analysis section, I see that I gave away my agency: "responsibilities led me to put my writing aside." I can't help but wonder how much of an impact that this thought pattern had on my two-year manuscript. How much time did I not claim for writing because my brain was telling me I was too busy? I will need to pay attention in the 
future for that way of thinking, in order to explore it and make a more informed choice about how I am spending my time.

\section{CONCLUSION}

Despite the challenges with writing the two-year manuscript, I was pleased to discover how much I enjoy doing research and enjoy scholarly writing. Engaging in reflective practice about the manuscript and implementing changes to my writing process has resulting in positive changes. Since the two-year manuscript was accepted in June 2019, I have authored this column and coauthored a paper published in July 2020. My initial choice of tools seems beneficial for now. Future reflection may suggest other areas and changes for improvement.

Librarians who are struggling with writing management may want to consider using reflection (individually or in conversation with one or more others) to uncover the underlying issues in order to select the best strategies for their situations. Participating in "Write on Site" sessions may sound like a great idea, but for someone whose writing challenges are structuring a document or wrestling with grammar, working with a writing tutor might be more appropriate solution. Once issues have been identified, it is easier to look for solutions or ask colleagues for solutions.

Why would someone admit their failure publicly like I did in this column, besides the obvious reason to help readers better understand writing management and reflective practice? I am reminded of those reflective conversations with my spiritual director - why do research and write for publication at all? It is important for me as a health science librarian to do what I can to learn more about what we do and how we can do it better. In this way, perhaps I am moving the profession forward a little bit by helping librarians learn to apply reflective practice in and beyond their writing practice. I believe in this enough to overcome my discomfort and write this column.

PS - I am interested in taking the reflection even further: What questions would you ask me about my initial writing process that might help me understand the situation more clearly? Is there something that I didn't consider? If you've found yourself in a similar situation, what helped you?

\section{REFERENCES}

1. Miller JM. Reflective practice and health science librarians: engagement, benefits, and barriers. J Med Libr Assoc. 2020 108(1):17-28.

https://dx.doi.org/10.5195/jmla.2020.777.

2. Holmes HN. Coming soon! Hypothesis: Failure. Hypothesis [Internet]. 2018 Fal-Win [cited 2019 Oct 1]; 30(1):5. <https://www.mlanet.org/d/do/13566>.

3. Constable G. Reflection as a catalyst in the development of personal and professional effectiveness. In: Mantell A, Scragg T, editors. Reflective practice in social work. 5th ed. Thousand Oaks, CA: SAGE Publications; 2019. p. 63-79. 
4. Driscoll J. Chapter 2, Supported reflective learning: the essence of clinical supervision? In: John Driscoll, editor. Practising clinical supervision: a reflective approach for healthcare professionals. 2nd ed. Philadelphia, PA: Elsevier; 2007. p. 27-50.

5. Jasper M. Beginning reflective practice. 2nd ed. Andover, Hampshire; 2013. Chapter 1: What is reflective practice?; p. 1-31.

6. Gibbs G. Learning by doing: a guide to teaching and learning methods. Oxford, UK: Oxford Centre for Staff and Learning Development; 1988 [cited 12 Mar 2020]. $<$ https://shop.brookes.ac.uk/product-catalogue/oxford-centre-for-staff- learningdevelopment/books-publications/ebooks/learning-by-doing-a-guide-to- teaching-andlearning-methods-by-graham-gibbs-ebook>.

7. Carroll R. The Bullet Journal Method: track the past, order the present, design the future. New York, NY: Portfolio/Penguin; 2018.

8. Cirillo F. The Pomodoro Technique [Internet] [rev. 2019; cited 23 Mar 2020]. $<$ https://francescocirillo.com/pages/pomodoro-technique>.

9. Lamott A. Bird by bird: some instructions on writing and life. New York, NY: Anchor; 1995. Chapter 3, Shitty first drafts; p. 20-6.

10. Ortlipp M. Keeping and using reflective journals in the qualitative research process. Qualitative Report [Internet]. 2008 Dec [cited 2020 Feb 20];13(4):695- 705. $<$ https://nsuworks.nova.edu/tqr/vol13/iss4/8>.

11. Mewburn I. Shut up and write [Internet]. 2011 Jun 14. [cited 2020 Aug 13]. $<$ https://thesiswhisperer.com/shut-up-and-write/>

12. Houfek JF, Kaiser KL, Visovsky C, Barry TL, Nelson AE, Kaiser MM, Miller CL. Using a writing group to promote faculty scholarship. Nurse Educ. 2010 JanFeb;35(1):41-5. DOI: https://dx.doi.org/10.1097/NNE.0b013e3181c42133.

13. Pennamon RE, Moss LJ, Springer SI. Scholarly writing groups: a source of support for early career counseling faculty and doctoral students. VISTAS Online [Internet]. 2016 [cited 2020 Mar 20]:article 72. <https://www.counseling.org/knowledgecenter/vistas/by-year2/vistas-2016/docs/default-source/vistas/article_72_2016>.

14. Skarupski KA, Foucher KC. Writing accountability groups (WAGs): a tool to help junior faculty members build sustainable writing habits. J Fac Dev [Internet]. 2018 Sep [cited 2020 Mar 20];32(3):47-54. $<$ https://www.hopkinsmedicine.org/fac_development/career_path/skarupski-wagsarticle.pdf>. 